\title{
A rara associação entre Saturnismo e Pseudogota
}

\author{
The rare association between Saturnism and Pseudogota \\ La rara associón entre Saturnismo y Pseudogota
}

Recebido: 10/05/2021 | Revisado: 16/05/2021 | Aceito: 30/05/2021 | Publicado: 01/06/2021

Átila Coelho Botelho Ponte
ORCID: https://orcid.org/0000-0002-2626-6216
Hospital Geral Dr. Waldemar Alcântara, Brasil
E-mail: atilacbp@gmail.com
Leonardo Rodrigues Melo
Hospital de Messejana, Brasil
ORCID: https://orcid.org/000-0001-567-3587
E-mail: leonardorodriguesmelo\#gmail.com
Luccas Victor Rodrigues Dias
ORCID: https://orcid.org/0000-0002-8428-4068
Hospital Geral Waldemar de Alcântara, Brasil
E-mail: luccasvictor4@gmail.com
Lucas Dourado Mapurunga Pereira
ORCID: https://orcid.org/0000-0001-5750-5294
Hospital Geral Waldemar de Alcântara, Brasil
E-mail: lucasdmapurunga@gmail.com
Fabricio André Martins da Costa
ORCID: https://orcid.org/0000-0002-7080-1386
Hospital de Messejana, Brasil
E-mail: fabricioamc18@gmail.com
Kristopherson Lustosa Augusto
ORCID: https://orcid.org/0000-0001-9254-9128
Universidade Federal do Ceará, Brasil
Universidade de Fortaleza, Brasil
Centro Universitário Christus, Brasil
E-mail: kristopherson@hotmail.com

\section{Resumo}

Relata-se o caso de um homem de 51 anos, que evoluiu insidiosamente com tetraparesia após ferimento cervical por arma de fogo há 19 anos, apresentando-se com poliartralgia, cefaleia, dor abdominal, constipação, polineuropatia e anemia. Diante da hipótese diagnóstica de saturnismo pelos elevados níveis séricos e urinários de chumbo, optou-se pela retirada cirúrgica do projétil em região cervical, obtendo-se melhora clínica. Após 5 meses foi readmitido com recidiva do quadro abdominal e anêmico. A tomografia de abdome evidenciou possível fragmento de projétil em músculo reto abdominal direito. Na internação, apresentou febre, poliartralgia com monoartrite em punho, e sinais flogísticos em abaulamento em cotovelo esquerdo, o qual foi puncionado. Devido relato na literatura de que a intoxicação por chumbo aumenta a reabsorção de ácido úrico no túbulo contorcido proximal e o antecedente de Gota relatado, tratamos o paciente com anti-inflamatórios e prednisona, com melhora clínica. $\mathrm{O}$ estudo do líquido revelou cristais de pirofosfato de cálcio, contrapondo o diagnóstico de artrite gotosa. O paciente foi submetido a cirurgia para retirada do projétil em músculo reto abdominal, sendo optado por não iniciar quelante devido ao nível sérico de chumbo inferior a 50mcg/dl e a melhora do paciente, que recebeu alta poucos dias após. Relatamos esse caso devido a raridade dessa associação, e assim, esperamos suscitar possível associação destas patologias, com mecanismo fisiopatológico desconhecido, ainda não descrito em livros de clínica médica, com apenas um caso publicado na literatura mundial. Palavras-chave: Intoxicação por Chumbo; Saturnismo; Pseudogota; Doença por depósito de Pirofosfato de Cálcio.

\begin{abstract}
Report the case of a 51-year-old man, who evolved insidiously with tetraparesis after firearm cervical injury 19 years ago, presenting with polyarthralgia, headache, abdominal pain, constipation, polyneuropathy and anemia. Given the diagnostic hypothesis of lead poisoning due to the high serum and urinary levels of lead, surgical removal of projectile in the cervical region was chosen, obtaining clinical improvement. After 5 months, he was readmitted with a relapse of the abdominal and anemic symptoms. Abdomen tomography revealed a possible projectile fragment on right rectus abdominis muscle. On hospitalization, he presented fever, polyarthralgia with fist monoarthritis and phlogistic signs on left bulging elbow, which was punctured. Literature review shows increased reabsorption of uric acid on lead poisoned patients added to the patient antecedent of Gout so we decide to treat the patient with anti-inflammatory drugs and
\end{abstract}


prednisone, with clinical improvement. The study of liquid revealed calcium pyrophosphate crystals, contrasting gouty arthritis diagnosis. Patient underwent surgery to remove the projectile in the rectus abdominis muscle, we decided not to prescribe chelating, due to the serum lead level below $50 \mathrm{mcg} / \mathrm{dl}$ and clinical patient improvement, who was discharged a few days later. We report this case due to the rarity of this association. We hope to raise a possible association of these pathologies with an unknown pathophysiological mechanism not yet described in medical clinic books and with only one case published in world literature.

Keywords: Lead poisoning; Saturnism; Pseudogota; Calcium Pyrophosphate Deposit Disease.

\section{Resumen}

El caso de un hombre de 51 años, que evolucionó con tetraparesia después herimiento cervical por arma de fuego hace 19 años, presentándose con poliartralgia, dolor de cabeza, dolor abdominal, constipación, polineuropatía y anemia. Delante de hipótesis diagnóstica de saturnismo por los altos niveles séricos y urinarios de plomo, fue escogida la retirada quirúrgica del proyectil en región cervical, obteniéndose mejora clínica. Después de 5 meses, fue readmitido con recaída del cuadro abdominal y anémico. Tomografía de abdomen evidenció posible fragmento de proyectil en muslo recto abdominal derecho. En la internación, presentó fiebre, poliartralgia con monoartritis en puño y signos flogísticos en codo abultado izquierdo, el cual fue puncionado. Por relatos en la literatura de intoxicación por plomo crece la reabsorción de ácido úrico en el túbulo contorcido proximal y el antecedente de la Gota relatado, tratamos el paciente con anti-inflamatorios y prednisona, con mejora clínica. El estudio del líquido reveló cristales de pirofosfato de calcio, contrastando el diagnóstico de artritis gotosa. Paciente fue a cirugía para retirada del proyectil en muslo recto abdominal, así eligiendo no empezar quelante, debido al nivel sérico de plomo inferior a 50mcg/dl y mejora del paciente, que recibió alta. Relatamos ese caso debido la raridad de esa asociación y así esperamos suscitar posible asociación de esas patologías, con mecanismo fisiopatológico desconocido, aun no descrito en libros de clínica médica, con sólo un caso publicado en la literatura mundial.

Palabras clave: Intoxicación por Plomo; Saturnismo; Pseudogota; Enfermedad por Deposición por Pirofosfato de Calcio.

\section{Introdução}

Saturnismo é uma patologia que possui grande correlação com a exposição ambiental, podendo gerar quadros de grave morbimortalidade. Outra forma de exposição é através da retenção de fragmentos de projéteis de arma de fogo, especialmente se em contato com o líquido sinovial ou cefalorraquidiano, que permitem a distribuição do chumbo no plasma.

Relatamos o caso de um paciente de 51 anos de idade que desenvolveu saturnismo após 19 anos de exposição ao chumbo presente em fragmentos de projétil de arma de fogo que ficaram alojados em seu organismo. Apresentou dois quadros de intoxicação aguda por chumbo, com necessidade de internamento hospitalar em novembro de 2013 e em abril de 2014 , quando apresentou quadro articular que, ao estudo do líquido sinovial, permitiu o diagnóstico de doença por deposição de pirofosfato de cálcio (DDPC).

Considerando a raridade desta associação, relatamos esse caso clínico e fizemos revisão da literatura a fim de revisarmos o saturnismo e seus aspectos clínicos, bem como buscarmos estudos que descrevam correlação fisiopatológica entre o saturnismo e DDPC.

\section{Metodologia}

Realizamos um estudo de caso de caraterística qualitativa por meio da ampla descrição do caso clínico em questão. No qual os dados foram obtidos através do acompanhamento de um paciente durante seu internamento no Hospital Geral Dr Waldemar de Alcântara (HGWA) - Fortaleza, CE em abril de 2014, bem como através da revisão do prontuário do internamento anterior do paciente no Hospital Geral de Fortaleza (HGF) - Fortaleza, CE, no mês de novembro de 2013. O paciente citado assinou termo de consentimento livre e esclarecido, e sua identidade foi preservada.

Realizamos, também, ampla revisão de literatura sobre os conceitos de saturnismo, gota e doença por depósito de pirofosfato de cálcio, através de pesquisa nas bases de dados da Biblioteca Virtual da Saúde e do PubMed utilizando os descritores DeCS e MeSH terms "Saturnismo", "Intoxicação por Chumbo", "Gota", "Pseudogota”, e "Doença por depósito de 
Pirofosfato de Cálcio" com definição dos artigos a serem utilizados como referência após a leitura dos estudos cujo resumo apresentassem dados que sugerissem a descrição do saturnismo, da gota saturnínica, da pseudogota e de possibilidade de associação entre saturnismo e doença por depósito de pirofosfato de cálcio.

\section{Resultados}

Paciente, 51 anos, sexo masculino, admitido com quadro de dor abdominal e anemia. Relatava ferimento por arma de fogo em região cervical há 19 anos e, desde então, quadro de tetraparesia, porém, com funcionalidade preservada após o evento. Em novembro de 2013, foi admitido no HGF por quadro de 9 meses de evolução de dor abdominal difusa em aperto, intensa, com alívio ao uso de analgésicos, e com piora pós-prandial. Associavam-se a esse quadro hiporexia, constipação, perda de $19 \mathrm{Kg}$ de peso no período (de $64 \mathrm{Kg}$ para $45 \mathrm{Kg}$ de peso), adinamia, cefaleia, poliartralgia e parestesia em mãos e pés. Com a piora dos sintomas, deixou de trabalhar, sendo admitido no HGF. Durante este internamento, foi aventada a hipótese de saturnismo, e o paciente foi submetido a neurocirurgia para retirada dos fragmentos alojados em coluna vertebral desde o trauma sofrido há 19 anos. Descreveu-se impossibilidade de retirada de todos os fragmentos, pois alguns não eram cirurgicamente acessíveis devido à sua localização perimedular (figura 1). Após a cirurgia, o paciente evoluiu com melhora progressiva. Os níveis de chumbo urinário em associação com o exame histopatológico, que revelou "alguns vasos e filetes nervosos com aparente impregnação basofílica", confirmaram o diagnóstico de saturnismo.

Figura 1 - Tomografia Computadorizada de coluna cervical evidenciando material com densidade metálica comprometendo o corpo vertebral de C5 a C7, determinando redução da amplitude do cone medular e obliteração completa dos canais de conjugação direitos neste nível.

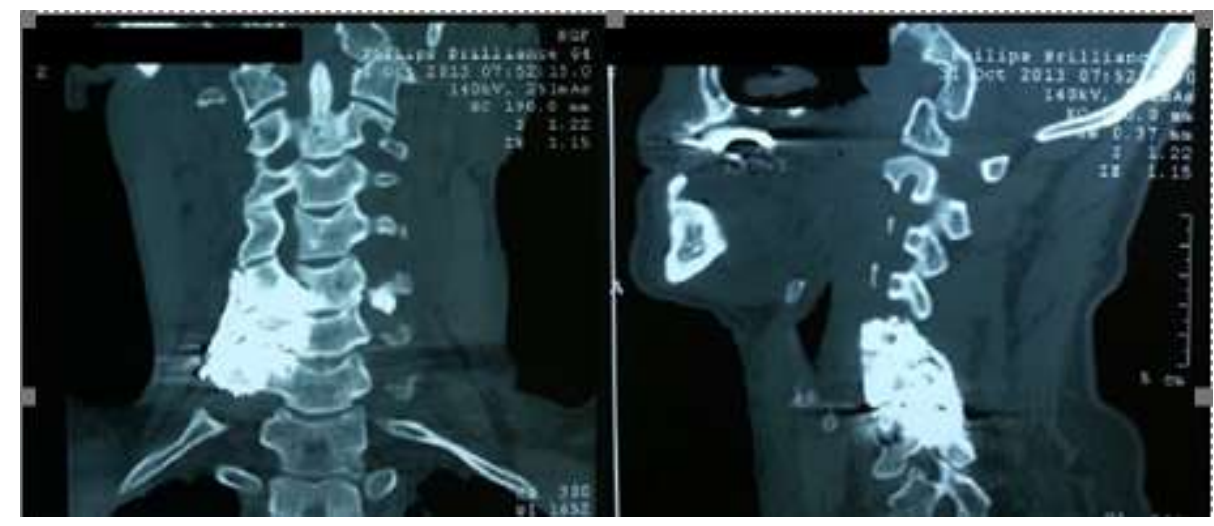

Fonte: arquivo pessoal do autor.

Em abril de 2014, o paciente voltou a apresentar dores abdominais intensas e adinamia. Buscou assistência médica no HGF, onde foi readmitido e, então, encaminhado ao HGWA para suporte clínico e investigação diagnóstica. À admissão, o paciente apresentava-se em regular estado geral, emagrecido e hipocorado, com pressão arterial de 120x80mmHg, pulso de 74bpm, frequência respiratória de 20irpm e sem alterações à ausculta cardiopulmonar. Ao exame abdominal, apresentava dor à palpação mesogástrica e massa palpável em região infraumbilical. Exames admissionais revelaram hemoglobina de 7,4g/dl, hematócrito de $21 \%$, VCM de $75 \mathrm{fl}$ e CHCM de 34g/dl. Obteve alívio da dor abdominal com o uso de analgésicos. Em investigação da anemia, apresentou provas para hemólise negativas. Os níveis de vitamina B12, de ferro sérico e de ferritina encontravam-se dentro da normalidade. Endoscopia digestiva alta e colonoscopia não identificaram sangramento ativo ou prévio. 
Tomografia computadorizada de abdome evidenciou "material metálico/calcificação em região posterior do músculo reto abdominal direito, ao nível do hipocôndrio, medindo cerca de 0,6cm" (figura 2). Foi avaliado pela equipe de Cirurgia Geral e decidido por retirada cirúrgica desse fragmento, considerando a possibilidade de novo quadro de saturnismo.

Figura 2 - Tomografia Computadorizada de Abdome evidenciando material Metálico/calcificação em região posterior do músculo reto abdominal direito, ao nível do hipocôndrio, medindo cerca de $0.6 \mathrm{~cm}$ (seta).

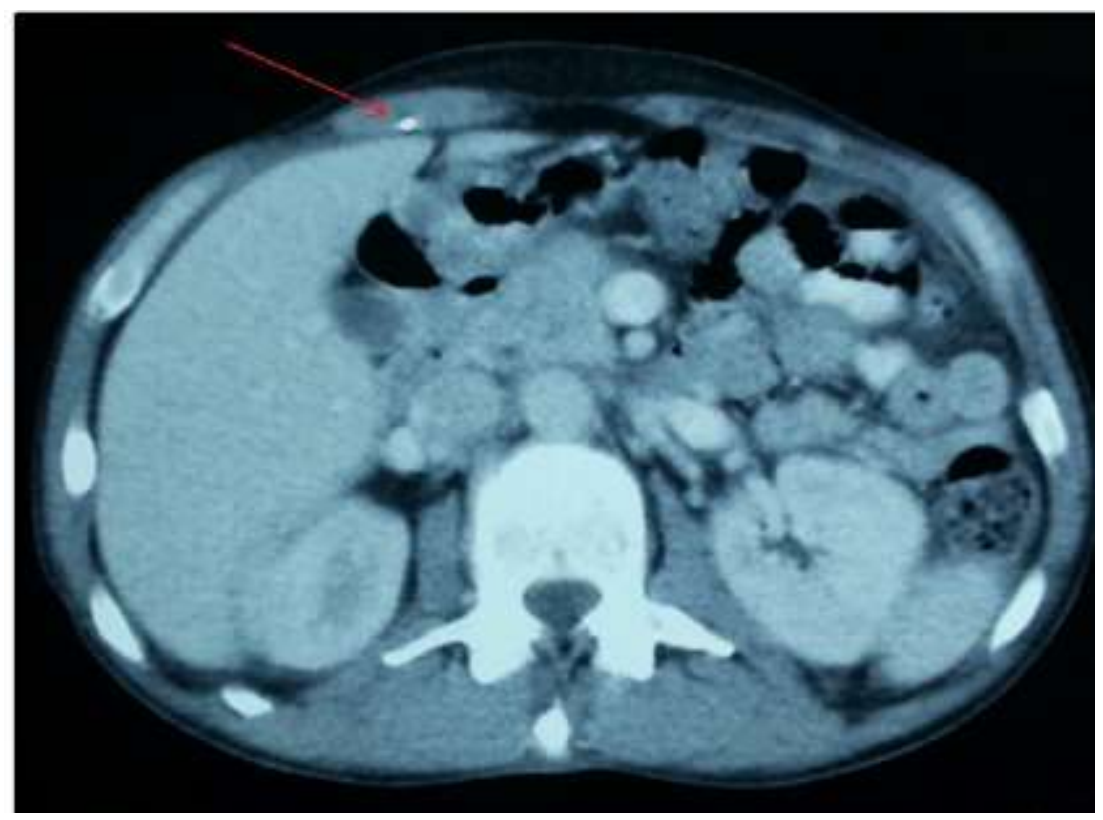

Fonte: arquivo pessoal do autor.

Enquanto aguardava a realização do procedimento, o paciente apresentou febre de $38^{\circ} \mathrm{C}$, sem calafrios, associado a dor em tornozelos, joelhos, punhos e cotovelos, com edema, calor e rubor em punho direito e aumento de lesão prévia em cotovelo esquerdo sugestiva de tofo gotoso. O paciente relatou ser portador de artrite gotosa há 5 anos, tendo realizado diversas punções de alívio em joelhos quando apresentava crises. Fazia uso irregular de colchicina, cetoprofeno e alopurinol. Foi optado por iniciar prednisona $0,5 \mathrm{mg} / \mathrm{dia}$ e realizar punção de bursa olecraniana esquerda, com retirada de líquido leitoso com microcristais visíveis (figura 03). O estudo do líquido revelou 330 células (30\% de linfócitos, 57\% de neutrófilos, $8 \%$ de monócitos e 3\% de eosinófilos) e 160 hemácias, bacterioscopia e cultura negativas, descartando quadro infeccioso, e presença de cristais de pirofosfato de cálcio (3+) e de colesterol (+), compatível com o diagnóstico de DDPC. Apresentou piora da anemia (níveis de hemoglobina caíram para 6,8g/dL) e níveis elevados de VHS (108mm). 
Figura 3 - A. Tofo em região olecraniana esquerda. B. Aspiração de Bursa olecraniana esquerda. Observa-se o aspecto leitoso do material aspirado de Bursa olecraniana esquerda do paciente. Observam se cristais na parede do frasco.

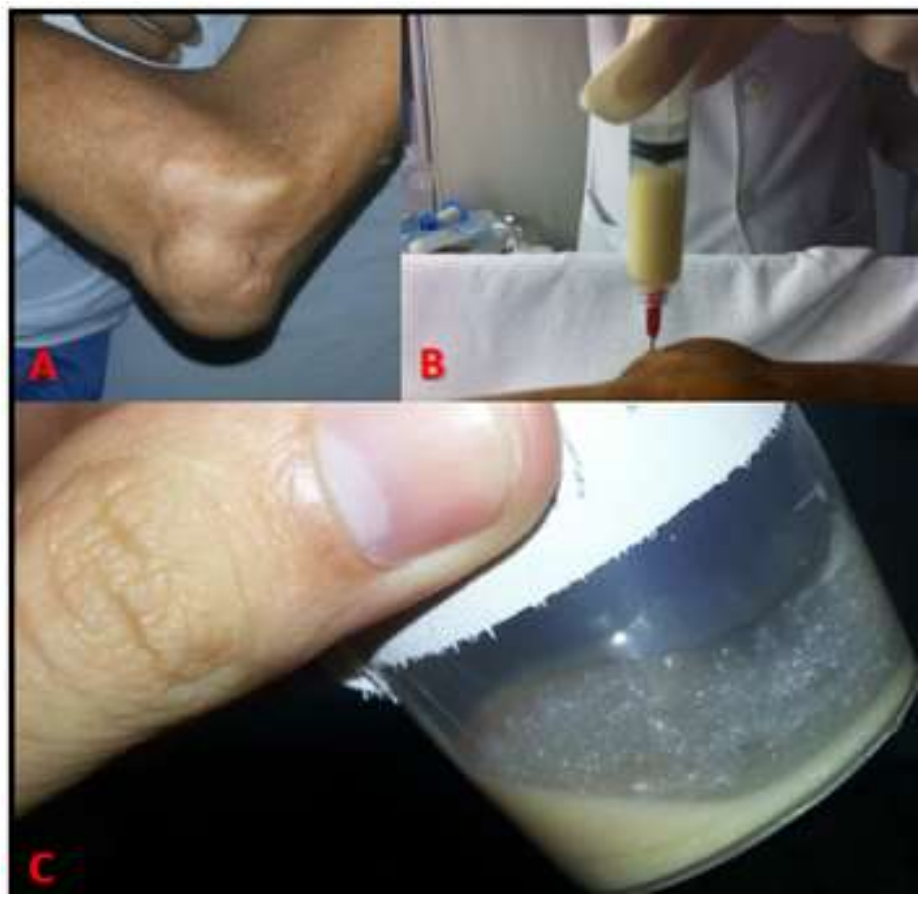

Fonte: Arquivo pessoal do autor.

O quadro articular regrediu completamente após 7 dias de uso da prednisona e o quadro de intoxicação por chumbo, após a retirada do fragmento de projétil de arma de fogo alojado em músculo reto abdominal direito. Os níveis de chumbo sérico e urinário foram de 30,6mcg/dl e 147,5mcg/g de creatinina, respectivamente, confirmando o diagnóstico de intoxicação aguda por chumbo, porém, não justificando ser necessário o uso de terapia com quelantes, haja vista a recomendação mais prevalente encontrada na literatura à época ser a realização desta intervenção terapêutica em caso de níveis séricos maiores que 50mcg/dl em pacientes sintomáticos. O paciente recebeu alta hospitalar com melhora progressiva do quadro clínico.

\section{Discussão}

\subsection{Aspectos Gerais e Históricos}

A intoxicação por chumbo (saturnismo), é uma condição de baixa suspeição, devido seus sintomas serem inespecíficos, mas cuja suspeita eleva-se ao ser considerado o contexto epidemiológico do paciente. Por ser um dos contaminantes tóxicos mais comuns, fica claro o porquê de sua principal forma de exposição ser a ambiental e a ocupacional. (Moreira \& Moreira, 2004). Outra forma de contaminação por chumbo é através da retenção de projéteis de arma de fogo no organismo. Apesar de fontes afirmarem a existência de menos de 100 casos de saturnismo por retenção de projéteis de arma de fogo relatados na literatura médica (Rentfrow et al., 2013), estima-se que o número de casos não diagnosticados seja maior, dado o comportamento crônico e indolente da intoxicação, bem como a sua baixa suspeição clínica.

\subsection{Fisiopatologia}

As vias pelas quais o chumbo entra no corpo humano são, principalmente, por ingestão e por inalação (Moreira \& Moreira, 2004), entretanto, a absorção cutânea também é descrita. Outra forma de absorção do chumbo é pela exposição direta 
ao metal por meio de projéteis de arma de fogo ou de seus fragmentos alojados em regiões do corpo que permitem o contato destes com o líquido sinovial ou líquido cefalorraquidiano, cujo $\mathrm{pH}$ ácido promove a solubilização do chumbo, o deslocamento para o plasma e, assim, a sua distribuição para órgãos e tecidos (Madureira et al., 2009). Uma vez absorvido, o chumbo, que não tem nenhuma função fisiológica no organismo, ou é excretado, principalmente pela urina e pelas fezes, ou é distribuído e armazenado no sangue, nos tecidos moles e nos ossos. Estima-se que $90 \%$ do chumbo armazenado no corpo estejam nos ossos e que somente cerca de 5\% encontrados no plasma é que são considerados a fração biologicamente ativa e com capacidade de atravessar as membranas celulares e gerarem efeitos tóxicos (Moreira \& Moreira, 2004). Segundo Moreira e Moreira J (2004) "Os tempos de meia-vida do chumbo nos três compartimentos são bastante diferentes, sendo estimado em 36 dias para o sangue, 40 dias para os tecidos moles e 27 anos para os ossos [...]”. Isso remete à importância dos estoques ósseos de chumbo para quadros de saturnismo, corroborando com hipóteses que argumentam que as fontes endógenas são as maiores fornecedoras e mantenedoras dos estoques plasmáticos do que as exógenas (Moreira \& Moreira, 2004).

Estudos realizados por Smith et al (1996) trouxeram ao conhecimento que a influência do chumbo armazenado no esqueleto para os quadros de intoxicação crônica e aguda são tão importantes quanto as influências da exposição e da absorção do chumbo no ambiente (Smith, Osterloh \& Flegal, 1996). Deste modo, qualquer condição clínica que gere aumento do metabolismo ósseo pode provocar intensificação da mobilização dos estoques ósseos de chumbo para o sangue e, assim, deflagrar quadro de intoxicação. Dentre as condições citadas, incluem-se o crescimento ósseo acelerado na infância, gravidez e lactação, os estados pós-menopáusicos e de desequilíbrio hormonal, entre outros (Moreira \& Moreira, 2004).

Nesse contexto, quadros de infecção, desequilíbrio acidobásico, cirurgias, osteoporose, tireotoxicose ou uso de determinadas drogas podem inesperadamente mobilizar o chumbo dos ossos para o plasma, gerando sintomatologia de intoxicação mesmo anos após a cessação da exposição (Moreira \& Moreira, 2004).

Uma vez no plasma, com a garantia da capacidade de cruzar as membranas celulares e o fato de ser um análogo biológico do cálcio, o chumbo pode interferir nas vias metabólicas do cálcio em diversos órgãos e sistemas e, a partir deste mecanismo, gerar os sintomas clássicos da intoxicação. De acordo com Moreno \& Granada (2012): "O chumbo tem grande afinidade pelos grupos sulfidrila, em especial pelas enzimas dependentes de zinco. O mecanismo de ação é complexo: aparentemente o chumbo interfere no metabolismo do cálcio, que o substitui e se comporta como um segundo mensageiro intracelular, ao alterar a sua distribuição nos compartimentos intracelulares e ao ativar a proteinoquinase. É capaz de unir-se à calmodulina mais avidamente do que o cálcio, e inibir a bomba de Na-K-ATPase, o que aumenta o cálcio intracelular. Esta alteração do cálcio explica em grande parte as manifestações neurológicas da intoxicação pelo chumbo".

Outra forma de lesão neuronal do chumbo é o seu acúmulo no espaço endoneural dos nervos periféricos, provocando edema e lesão axonal. Ao ligar-se aos grupamentos sulfidrila das metaloenzimas, o metal interfere na síntese do heme e promove o desenvolvimento de anemia.

Ao nível renal, compromete a ativação da vitamina D e permite a formação de inclusões intranucleares nos túbulos renais, podendo provocar atrofia tubular e fibrose, com preservação da estrutura glomerular e desencadeando proteinúria seletiva (Moreno \& Granada, 2012).

\subsection{Manifestações Clínicas}

O chumbo inorgânico tem potencial para afetar diversos sistemas, sendo os mais sensíveis o hematopoiético, o nervoso central e o renal. A intensidade das manifestações clínicas depende do tempo e do grau de exposição, bem como da sensibilidade 
individual. Assim, como o saturnismo apresenta-se com sintomas iniciais bastante inespecíficos, se não houver uma história exposicional bem relatada, a suspeição clínica para esse diagnóstico torna-se fraca.

As manifestações clínicas iniciais geralmente remetem às alterações no sistema nervoso central, com sintomas como fadiga, astenia, letargia, cefaleia, insônia, hipotenacidade, perda de memória e tremores, podendo, em quadros mais graves, evoluir para encefalopatia, queda do nível de consciência, quadros convulsivos e sintomas de hipertensão intracraniana por edema cerebral (Moreno \& Granada, 2012). Associam-se ao quadro inicial, também, anemia microcítica e hipocrômica, perda da função renal e artralgias (Rentfrow et al., 2013).

Segundo Valente et al. (2014), a dor abdominal em cólica é a principal manifestação gastrointestinal, apesar de ainda não ter sua etiopatogenia bem elucidada. Associado a esse quadro podem ocorrer náuseas, vômitos, anorexia, constipação e diarreia, podendo facilmente simular um quadro de abdome agudo. Reforçando essa descrição, há relatos e dados na literatura médica que apontam o saturnismo como uma das causas mais comuns de intervenções cirúrgicas abdominais sem achados.

Os pacientes podem evoluir com nefropatia, que é progressiva e irreversível, a depender do tempo de exposição, e geralmente acompanhada de hipertensão arterial sistêmica. Além disso, descrevem-se quadros de artralgia, por vezes associadas a artrite gotosa (Valente et al., 2014). Advoga-se que o saturnismo seja um fator de risco para o desenvolvimento desta entidade justamente por sua nefrotoxicidade ter o potencial de reduzir a excreção urinária de ácido úrico (Dalvi \& Phillinger, 2013). Outro achado clínico, este semiologicamente clássico e bastante sugestivo, embora não seja patognomônico do saturnismo, são as linhas de Burton, que são linhas azuladas nas gengivas secundárias à deposição de sulfeto de chumbo.

\subsection{Diagnóstico}

O saturnismo é uma condição clínica cujas manifestações iniciais, por serem inespecíficas, tornam sua consideração como hipótese diagnóstica inicial de baixa presunção. Geralmente, a evidência de um relato de exposição crônica ou intensa ao chumbo é que traz à tona essa condição como possibilidade.

Uma vez suspeitada, a intoxicação pelo chumbo pode ser avaliada laboratorialmente pela dosagem direta do chumbo sanguíneo (plumbemia) ou urinário (plumbúria) ou pela medida de parâmetros indiretos dos efeitos do chumbo na hematopoese, como a elevação dos níveis do ácido delta-aminolevulínico urinário (ALA-U), do coproporfobilinogênio na urina (CPU) ou da protoporfirina IX em sua forma ligada ao zinco (ZPP) ou livre (EP) ou, ainda, pela diminuição na atividade do ácido deltaaminolevulínico desidratase (ALA-D) (Valente et al, 2014).

\subsection{Tratamento}

A partir da revisão de literatura realizada para a confecção deste artigo, observamos que não há um consenso que determine uma padronização da terapia específica para casos de intoxicação por chumbo. $\mathrm{Na}$ verdade, o que se considera consensual na abordagem de todo paciente com quadro de saturnismo é a necessidade de afastamento do indivíduo da fonte de exposição ao metal, seja ela ambiental ou ocupacional. Entra nesse contexto, a remoção cirúrgica de eventuais fragmentos de projéteis de arma de fogo ou de quaisquer outros componentes que contenham chumbo e que estejam alojados no corpo do paciente. A terapia específica para o tratamento da intoxicação aguda por chumbo é a quelação com compostos que se ligam de forma estável ao metal e aumentam a sua excreção renal ou biliar. As drogas mais conhecidas são o dimercaprol (BAL), o ácido 2,3-dimercaptosuccínico (DMSA), a D-penicilamina, o ácido dimercaptopropanosulfônico (DPMS) e, o mais conhecido e utilizado em nosso meio, o edetato cálcico dissódico (EDTACaNa 2$)$. 
A almeida et al (2010) afirma e recomenda que: "Não há consenso quanto aos esquemas terapêuticos para o tratamento quelante nos casos de intoxicação por chumbo. Já Rentfrow et al (2013) recomenda que a terapia com quelantes de chumbo seja realizada em todos os pacientes com plumbemia $>100 \mathrm{mcg} / \mathrm{dl}$, que deve ser individualizada em pacientes com níveis de plumbemia entre 80 e $100 \mathrm{mcg} / \mathrm{dl}$ e que deve ser realizada em todos os pacientes sintomáticos e com níveis > 50mcg/dl, embora reforce a inexistência de consenso.

$\mathrm{O}$ tratamento com quelantes em longo prazo em pacientes portadores de depósitos importantes de chumbo ósseo não são eficazes, efetivos, praticáveis ou providos de lógica terapêutica sob a luz dos estudos atuais, deixando como alternativa terapêutica a remoção cirúrgica dos fragmentos de projéteis de arma de fogo, isso se necessário (quadro clínico persistente) e se viável (acesso cirúrgico). Além disso, o ponto inicial e de maior importância para um tratamento adequado do saturnismo é a cessação da exposição ao chumbo. (Valente et al., 2014).

\subsection{Saturnismo e Artropatia por Cristais}

Uma manifestação crônica da intoxicação pelo chumbo é a gota. São vários os fatores que predispõem à gota em uma intoxicação por chumbo, todos eles associados ao estado de hiperuricemia. Essa pode ser decorrente de uma superprodução sistêmica do ácido úrico ou de uma excreção reduzida de urato secundária ao quadro de nefropatia. (Dalvi \& Phillinger, 2013).

A superprodução de ácido úrico nos quadros de Saturnismo é causada por alteração no metabolismo das purinas, porém o seu mecanismo é pouco estabelecido na literatura. Primeiramente o chumbo reduz a atividade da enzima aminohidrolase guanina, que catalisa a conversão de guanina em xantina. Com essa inibição, há acúmulo de nucleotídeos de guanina, aumentando a produção de monofosfato de inosina, elevando a produção de urato. O segundo mecanismo decorre da genotoxicidade, que interfere na atividade das enzimas responsáveis pela reparação de DNA e pela produção de radicais livres. (Dalvi \& Phillinger, 2013).

A nefropatia por chumbo, apesar de reconhecida como mecanismo importante para hiperuricemia, tem sua fisiopatologia ainda incerta. Uma doença intersticial é notada, reduzindo a eliminação de ácido úrico. Alguns estudos sugerem uma relação inversamente proporcional ao clearance de creatinina com os níveis séricos de chumbo ou que a redução da taxa de filtração glomerular (TFG) pode ser reversível após terapêutica quelante do metal (Dalvi \& Phillinger, 2013).

Algumas características do comprometimento articular diferem do quadro de gota primária. A gota secundária ao saturnismo tem uma predileção pela articulação do joelho, não há história familiar de doença articular e há uma relativa equivalência em ambos os sexos (Dalvi \& Phillinger, 2013).

A gota e a DDPC, antigamente chamada de pseudogota, são artropatias inflamatórias por deposição de cristais, porém, diferem em relação à fisiopatologia. Na DDPC, o sal de pirofosfato de cálcio pode depositar-se na cartilagem hialina, na fibrocartilagem ou na membrana sinovial, podendo, assim, simular várias doenças articulares. Atualmente, suas manifestações clínicas são divididas em osteoartrite, artropatia aguda ou crônica (TSUI, 2012).

Existem fatores de risco para formação desses cristais e desencadeantes, ocasionando um quadro agudo da doença. Dentre os fatores predisponentes, temos a idade avançada (o risco dobra a cada década entre 45-85 anos), hereditariedade (mutação dos cromossomos 8q e 5p), alterações metabólicas (hiperparatireoidismo, hipotireoidismo, hipofosfatemia e hipomagnesemia), injúria articular prévia e osteoartrite. Como gatilhos, temos trauma articular direto, quadros sistêmicos agudos (infecção), cirurgias ou hemotransfusão (Zhang et al., 2011).

O tratamento é baseado no alívio dos sintomas, uma vez que não há opção farmacológica viável para modular a formação ou para dissolver os cristais de pirofosfato de cálcio. Isso demonstra que a fisiopatologia ainda é incerta (Zhang et al., 2011). 
Existe influência genética bem definida nas duas patologias. O chumbo pode causar uma genotoxicidade e induzir mutações genéticas, e a DDPC pode ter origem de alterações cromossômicas, como fator predisponente. Porém, não há correlação conhecida entre esses dois mecanismos nem associação fisiopatológica descrita entre eles. Durante a extensa revisão de literatura, não encontramos relatos da associação entre essas duas patologias, à exceção do relato supracitado, tornando nosso relato relevante para impulsionar maiores estudos sobre o caso.

Observando essa associação clínica, vimos que o quadro articular relatado pelo paciente como artrite em joelhos de repetição ao longo de cinco anos e com alívio ao uso de colchicina, cetoprofeno e após punções de alívio, podemos considerar clinicamente sugestivo de gota satúrnica. No entanto, o paciente negou ter realizado qualquer investigação ao longo desse período, não havendo, portanto, confirmação desta hipótese até o internamento em nosso serviço. Como, durante o internamento, o paciente apresentou quadro articular e, ao estudo do líquido sinovial aspirado em bursa olecraniana esquerda, evidenciou-se a presença de cristais de pirofosfato de cálcio com ausência de cristais de monourato de sódio, firmou-se o diagnóstico de doença por depósito de pirofosfato de cálcio. Esse fato chamou a atenção da equipe médica assistente, haja vista não haver correlação formal e precisa entre saturnismo e DDPC na literatura.

Motivados por essa correlação atípica, realizamos revisão da literatura médica e encontramos apenas um artigo publicado em 1983 relatando dois casos clínicos de gota satúrnica com concomitante quadro de DDPC (Daniel et al, 1983).

\section{Considerações Finais}

O saturnismo é uma condição clínica que possui importante correlação à exposição, principalmente laboral e ambiental, com importante morbidade e mortalidade, devendo ser bem estudado e apresentado à comunidade. É conhecida a relação entre saturnismo e gota, mas sua associação com doença por depósito de cristais de pirofosfato de cálcio foi relatada somente em um trabalho de 1983. Sendo assim, suscitamos a possibilidade de haver uma marcada correlação fisiopatológica entre essas duas entidades clínicas e a necessidade de mais estudos para melhor esclarecer a existência dessa associação, com a finalidade de prover mais conhecimentos para a comunidade médica e, assim, definir estratégias de prevenção e de abordagem precoce.

\section{Referências}

Almeida et al.(2010). Uso de EDTACaNa2 por via intramuscular no tratamento de intoxicação por chumbo: a propósito de um caso clínico. Revista Brasileira de Toxicologia, 23(1-2), 28-34.

Cavaleiro-Costa, R.; Stape, C.A. \& Suzuki, I.(1994). Saturnismo causado por projétil de arma de fogo no quadril. Rev Bras Ortop, $29(6), 374-378$.

Dalvi, S.R. \& Phillinger, M.H.(2013). Saturnine gout, redux: a review. The American Journal of Medicine, 126(5), $450-458$.

Daniel, W.W. \& Wess, S.J.(1983). Intra-articular milk of calcium in saturnine gout. Radiology, 137, 389-392.

Ludke, M. \& Andre, M. E . D. A. (2013). Pesquisas em educação: uma abordagem qualitativa. São Paulo: E.P.U.

Madureira et al.(2009). Lead poisoning due to gunshot bullet in contact with cerebrospinal fluid: case report. São Paulo Medical Journal, 127(1), 52-54.

Mayo Clinic.(2019). Lead Poisoning, Definition. http://www.mayoclinic.org/diseases-conditions/lead-poisoning/basics/definition/con-20035487

Mayo Clinic.(2019). Lead Poisoning, Test and diagnostics. http://www.mayoclinic.org/diseases-conditions/lead-poisoning/basics/tests-diagnosis/con-20035487 Mayo Clinic,(2019). Lead Poisoning, TreatmentsandDrugs. http://www.mayoclinic.org/diseases-conditions/lead-poisoning/basics/treatment/con-20035487\

McCarty, D.J.; Kohn, N.N. \& Faires, J.S.(1962). The significance of calcium phosphate crystals in the synovial fluid of arthritis patients: the "pseudogout syndrome": I. Clinical aspects. Ann Intern Med, 56, 711.

Montes-Santiago, J.(2013). The lead-poisoned genius: Saturnism in famous artists across five centuries. In Stanley Finger, Dahlia W. Zaidel, François Boller and Julien Bogousslavsky. Progress in Brain Research, 203, 223-240.

Moreira, F.R. \& Moreira, J. C.(2004). A cinética do chumbo no organismo humano e sua importância para a saúde. Ciência \& Saúde Coletiva, 9(1), 167-181. 
Research, Society and Development, v. 10, n. 6, e29410615967, 2021

(CC BY 4.0) | ISSN 2525-3409 | DOI: http://dx.doi.org/10.33448/rsd-v10i6.15967

Moreno, A. \& Granada, J.(2012). Intoxicación por plomo: diagnóstico diferencial de dolor abdominal crónico. Reporte de caso y revisión de tema. Universitas Médica, 53(2), 199-207.

Pereira, A.S et al.(2018). Metodologia do Estudo de Caso. Metodologia da pesquisa científica. Ed. UAB/NTE/UFSM, 63-74.

Rentfrow et al.(2013). Lead toxicity and management of gunshot wounds in the lumbar spine. European Spine Journal, 22(11), $2353-2357$.

Robinson, P.C. \& Horsburgh, S.(2014). Gout: Joints and beyond, epidemiology, clinical features, treatment and co-morbidities. Maturitas, 78(4), 245-251.

Sadao, M.(2002). Intoxicação por chumbo. Revista de Oxidologia , 37-42.

Salgado, P.E.T.(2003). Metais em Alimentos. Fundamentos de Toxicologia, 2, 411-415.

Smith, D.R. \& Osterloh, J.D. \& Flegal, A.R.(1996). Use of Endogenous, Stable Lead Isotopes to Determine Release of Lead from the Skeleton. Environmental Health Perspectives, 104(1), 60-66.

Steinbach, L.S. \& Resnick, D.(2000). Calcium pyrophosphate dihydrate crystal deposition disease: imaging perspectives. Curr Probl Diagn Radiol, 29(6), 20929.

Tsui, F.W.(2012). Genetics and Mechanisms of Crystal Deposition in Calcium Pyrophosphate Deposition Disease. Current Rheumatology Reports. 14(2), 155160.

Valente et al.(2014). Saturnismo por retenção de projétil de arma de fogo em articulação: relato de caso. Revista da Sociedade Brasileira de Clínica Médica, 12(1), 64-68.

Zhang, W. et al.(2011). European League Against Rheumatism recommendations for calcium pyrophosphate deposition. Part I: terminology and diagnosis. Annals of Rheumatic Diseases: The EULAR Journal, 70(4), 563-570. 